\title{
A novel approach to predict the steady state temperature in ports and case of swash plate type axial piston machines
}

\author{
M. Zecchi, A. Mehdizadeh, and M. Ivantysynova \\ Maha Fluid Power Research Center, Purdue University, 1500 Kepner Dr. Lafayette, IN, USA 47905
}

\begin{abstract}
This paper presents a model able of predicting the working temperature of the hydraulic fluid in the case volume and outlet port of axial piston machines. For the first time the working temperature is estimated accounting for the power losses associated with the fluid flow in the lubricating interfaces, the churning motion of the oil in the machine case and the losses due to the compressibility of the hydraulic fluid. The paper illustrates a thorough comparison between the calculated and the measured case and outlet port temperatures for steady state operation of the axial piston machine.
\end{abstract}

Keywords: Axial piston machines, Heat transfer, Churning losses, Case temperature

\section{Introduction}

Current advanced developments in the fluid power systems technology, such as displacement controlled actuation, power split and hydraulic hybrid transmissions, use variable displacement axial piston units directly as control element. The units are therefore forced to operate over a much wider range of operating conditions compared to standard load sensing and similar systems, in terms of speed, displacement and differential pressure. These types of applications expect the axial piston unit to maintain a very high efficiency under extremely varying operating conditions, introducing a significant challenge for the designers. The performance and level of energy dissipation in axial piston machines is determined by the design of the rotating group and the design of the three main lubricating interfaces between piston and cylinder, cylinder block and valve plate and slipper and swash plate.

A cross section of the rotating group of a swash plate type axial piston machine is represented in 1 . The main lubricating interfaces between parts in relative motion are highlighted The lubricating interfaces represent a key design element, because they have to fulfill simultaneously a bearing and a sealing function: the film of lubricant is fundamental to properly support the high oscillating external loads, avoiding metal to metal contact, but the clearance between the parts is subjected to leakages of lubricant from high to low pressure regions and also to viscous dissipation associated with the fluid flow. The lubricating interfaces are most of the times the major source of power losses. A deep understanding of the behavior of the fluid film in these interfaces will allow for improved designs, which can rise the overall axial piston machine efficiency especially at partial load conditions, through computational design. Research towards computational design of positive displacement machines has made major progresses in the recent years. The computer aided

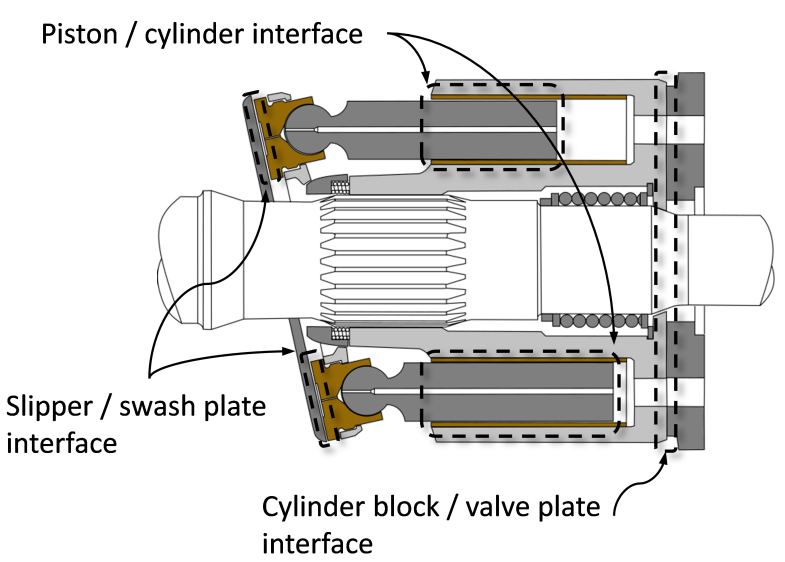

Figure 1: Three main lubricating interfaces in swash plate type axial piston machines.

design of axial piston machines has seen substantial developments and it is starting to gain a fundamental importance in industry. Nevertheless, recent studies ([1], [2]) have demonstrated that a reliable and accurate prediction of the lubricating interfaces performance can be achieved only if different physical phenomena are coupled together. Moreover, latest studies pointed out that the thermal behavior of the lubricating interfaced is particularly critical for two reasons. First, the solution of the non-isothermal fluid flow is fundamental to correctly estimate the viscosity of the lubricant and therefore the load carrying ability of the interface; second the temperature distribution in the machine solid parts during operation of the units causes thermal deflections which are of the same order of magnitude of the fluid film thickness, leading to substantial modifications of the geometry of the resulting fluid film. Advanced fluid structure interaction models are able of 
capturing the described phenomena, but one of their current limits is the definition of the boundary conditions to be applied in the thermal analysis. The prediction of the lubricating interfaces performance is extremely sensitive to the temperatures of the surrounding material and depends strongly on the temperature of the case and machine ports. Usually these temperatures are known from measurements, but during the design of new units such information is not available. The goal of the author's research study was to develop a model, which can predict the temperature of the fluid in the case and at the outlet port of the machine for a given inlet temperature of the fluid while the machine runs under steady state conditions. The in this paper presented model represents a new important step towards computational design of pumps and motors.

\section{Heat exchange in the axial piston machine}

The case and the outlet volumes are represented in Fig. 2. The case volume is defined by the hydraulic fluid filling the machine's housing, the outlet control volume by the hydraulic fluid in the high pressure port and in all the displacement chambers connected with it. The temperature is assumed to be

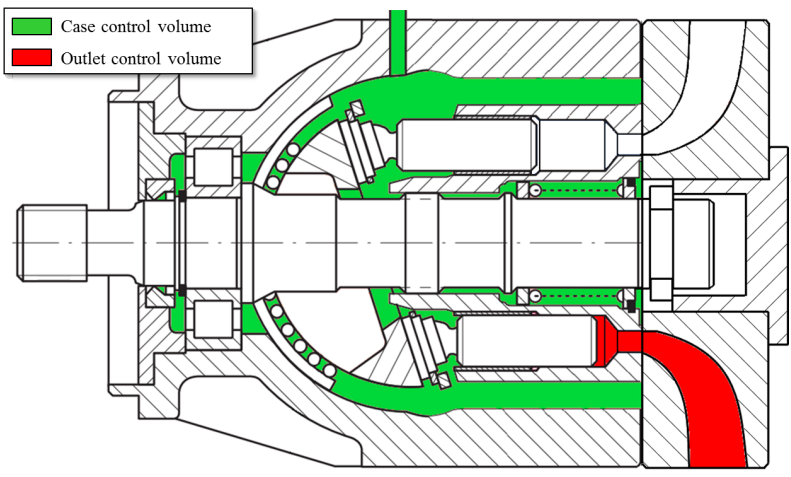

Figure 2: Definition of the control volumes

uniform throughout the volumes and since steady state conditions apply, the time variation is not of interest. The overall heat exchange can therefore be reduced to a lumped parameter representation. Each control volumes, exchanges mass, work and heat with the exterior, as illustrated schematically in Fig. 3. The mass flow rate $\dot{m}_{i}$ entering in the machine through the inlet port is then transferred to the outlet volume. If the unit works as a pump, and some load is applied, work is made by the displacement volume to pressurize the fluid. When a pressure difference is present between the two ports, the outlet mass flow rate $\dot{m}_{o}$ will differ from the inlet mass because of different source of volumetric losses. The mass flow $\dot{m}_{l, e}$ represents the total external leakage (or case flow) resulting from leakage flow between pistons and cylinders, cylinder block and valve plate and between slippers and swash plate. Another important source of loss impacting the effective outlet flow is caused by the non ideal timing of the valve plate combined with the compressibility of the fluid, which generates a backflow from the outlet port to the displacement chamber, as illustrated in. The dotted line indicates the theoretical

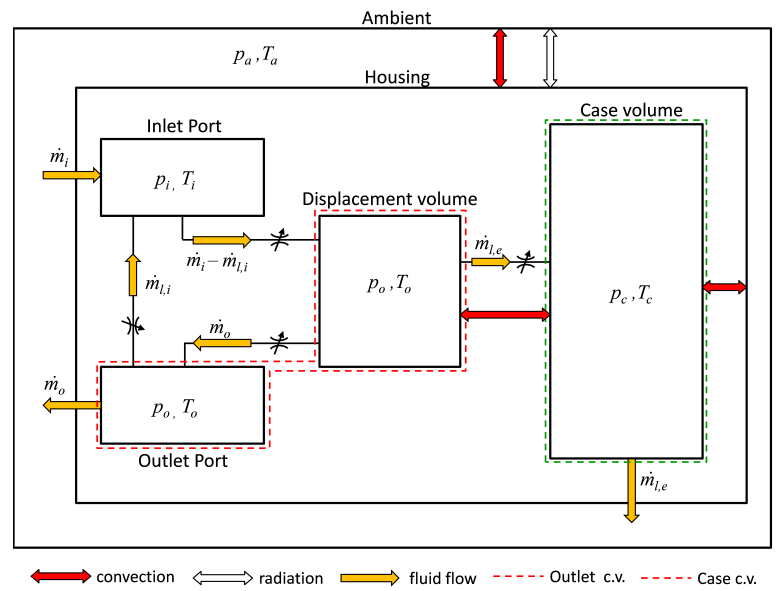

Figure 3: Schematic of the heat and mass transfer in the axial piston machine.

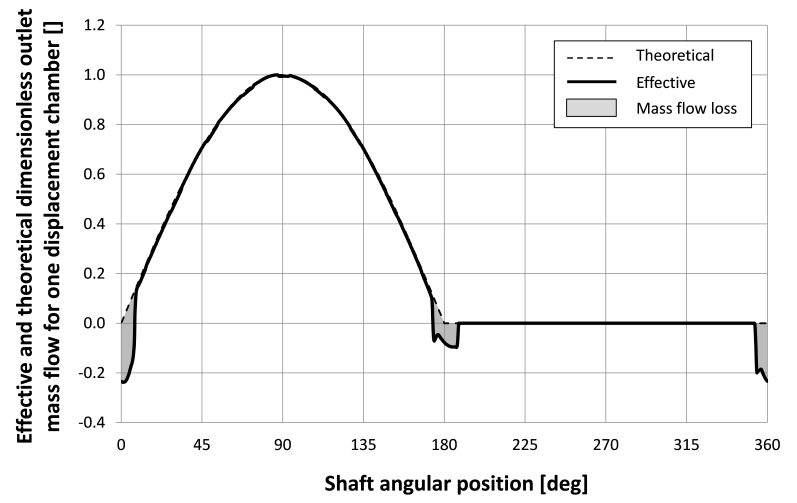

Figure 4: Effect of oil compressibility on the outlet mass flow rate associated to one displacement chamber.

dimensionless outlet mass flow associated with one displacement chamber, which is just a function of the kinematics of the machine; the solid line depicts the actual dimensionless mass flow. The difference between the two lines is due to the fact that when the displacement chamber opens to the valve plate port the fluid is at lower pressure and therefore a backflow occurs with an impact on the effective outlet mass flow rate. Furthermore, depending on the valve plate design, the inlet and outlet ports can be connected through the displacement chamber; in this case an amount of fluid is not properly delivered because it flows back from the high to the low pressure port; this volumetric loss is called internal leakage. The rate of mass associated with compressibility and internal leakage is indicated with $\dot{m}_{i, l}$ in Fig. 3

The heat transfer is included with a quite simple approach, considering forced convection between displacement and case volumes, natural convection and radiation between machine's housing and ambient. The governing equation is the expression of the energy conservation for an open system: with reference to the schematic of Fig. 5, the following equation applies for each control volume

$$
\sum \dot{m}_{i} h_{i}-\sum \dot{m}_{o} h_{o}+\dot{Q}-\dot{W}=0
$$


In Eq. $1 \dot{m}$ is the mass flow rate, $h$ the enthalpy, $\dot{Q}$ is rate of heat flow into the control volume and $\dot{W}$ is the rate of work done by the control volume. Figure 3 illustrates a schematic representation of the heat and mass flows associated with the axial piston machine operation. In the next two sections Eq.

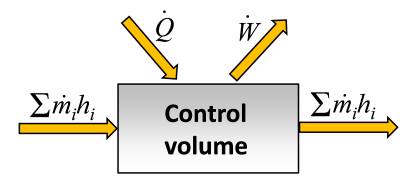

Figure 5: Schematic representation of the mass, heat and work exchanged by a control volume

1 will be applied to the outlet and case control volumes, generating a system of two equations in the two unknown temperatures in the case $T_{c}$ and outlet volumes $T_{o}$.

\subsection{Energy balance for the outlet control volume}

The outlet control volume is defined as the volume enclosed by the outlet port and the volume of all the displacement chambers connected with it. Assuming pumping operation, after being compressed, the mass flow taken from the inlet is partially lost through leakages in the lubricating interfaces and is then delivered at the outlet. Regardless of whether the mass flow leaves the volume as leakage or actual discharge flow its thermodynamic state is the same, being defined by the conditions at the outlet. Therefore, the two summations in Eq. 1 can be written as follows:

$$
\dot{m}_{i}\left(h_{i}-h_{o}\right)
$$

The enthalpy's differential can be expressed as follows

$$
d h=\left(\frac{\partial h}{\partial T}\right)_{p} d T+\left(\frac{\partial h}{\partial p}\right)_{T} d p
$$

The first term in Eq. 3 is the definition of specific heat capacity at constant pressure, while it can be demonstrated [3] that the second term is related to the volumetric expansion of the fluid. Equation 3 can therefore be rewritten as a function of pressure and temperature as follows

$$
d h=c_{p} d T+(1-\gamma T) \frac{d p}{\rho}
$$

where $c_{p}$ is the specific heat capacity at constant pressure, $\gamma$ is the fluid's coefficient of volumetric expansion and $\rho$ is the fluid's density. Equation 4 can be approximated to express a finite difference and applied to the case of Eq. 2 as follows

$$
h_{i}-h_{o} \approx c_{p}\left(T_{i}-T_{o}\right)+\left(1-\gamma T_{i}\right) \frac{\left(p_{i}-p_{0}\right)}{\rho_{i}}
$$

The outlet control volume also exchanges work with the fluid: if the unit operates as a pump, work is made on the fluid by the pumping action of the pistons; if the unit operates as a motor, work is done by the pressurized fluid on the pistons. In both cases the rate of work can be expressed as follows

$$
\dot{W}=\beta V_{o} n\left(p_{i}-p_{o}\right)=\dot{m}_{i} \frac{p_{i}-p_{o}}{\rho_{i}}
$$

where $p_{o}$ is the pressure in the displacement volume, $\beta$ is the displacement angle (in percentage with respect to the maximum value), $V_{0}$ is the geometric displacement of the unit and $n$ is the speed of the unit. The work is negative in pumping mode and positive in motoring mode. In this way, according to Eq. 1, the energy content of the fluid in the control volume increases in the first case and decreases in the second case. In Eq. 6 it is assumed that exactly half of the $z$ displacement chambers are actually part of the outlet control volume.

Regarding the heat transfer, it is assumed that the heat is exchanged with the cylinder block and the end case through forced convection. The rate of heat flow has been expressed through the Newton's law of cooling as follows:

$$
\dot{Q}_{f c v}=z \alpha_{D C}\left(\overline{A_{D C}}+A_{o c}\right)\left(T_{c}-T_{o}\right)
$$

where $\overline{A_{D C}}$ is the average area of one displacement chamber which exchanges heat with the cylinder block body over one shaft revolution and $A_{o c}$ is the inner surface of the outlet port; $\alpha_{D C}$ is the average convection coefficient associated with the fluid flow in these surfaces. The fluid temperature is $T_{o}$ and $T_{C}$ is the temperature of the wall. The temperature of the inner surface of the displacement chambers and outlet port is indeed unknown, but it is reasonable approximation to assume that they are at the same temperature of the fluid in the case.

By combining Eq. 5, 6 and 7 the energy balance for the outlet control volume yields:

$$
\begin{array}{r}
\dot{m}_{i}\left[c_{p}\left(T_{i}-T_{o}\right)+\left(1-\gamma T_{i}\right) \frac{\left(p_{i}-p_{0}\right)}{\rho_{i}}\right]+ \\
+z \alpha_{D C} \overline{A_{D C}}\left(T_{c}-T_{o}\right)-\dot{m}_{i} \frac{p_{i}-p_{o}}{\rho_{i}}=0
\end{array}
$$

In case of motoring mode operation, the pressurized region is the inlet and the leakage will occur mostly there. Therefore, the mass flow of interest is the outlet one and Eq. 9 changes as follows:

$$
\begin{array}{r}
\dot{m}_{o}\left[c_{p}\left(T_{i}-T_{o}\right)+\left(1-\gamma T_{i}\right) \frac{\left(p_{i}-p_{0}\right)}{\rho_{i}}\right]+ \\
+z \alpha_{D C} \overline{A_{D C}}\left(T_{c}-T_{o}\right)-\dot{m}_{o} \frac{p_{i}-p_{o}}{\rho_{i}}=0
\end{array}
$$

It shall be noticed that the work done on the fluid has an opposite sign in case of pumping or motoring mode operation. In the first case that contributes to raising the outlet temperature, while in the second case to lower it.

\subsection{Energy balance for the case control volume}

The case control volume is subjected to two major heat sources: the heat coming from the viscous dissipation associated with the fluid flow in the lubricating interfaces and in the heat generated due to the rotation of the cylinder block and pistons in the oil filled case. On the other hand, heat is removed from the case volume thanks to different heat transfer phenomena.

The first cooling effect is determined by the external leakage $\dot{m}_{l, \text { ext }}$; the situation is sketched in Fig. 6 in the case of 


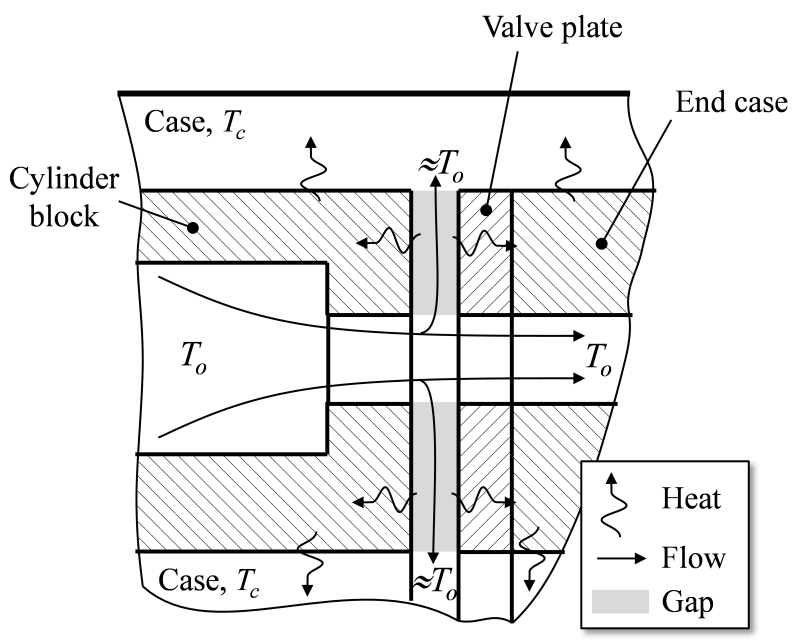

Figure 6: Schematic representation of the external leakage flow through the cylinder block valve plate interface and the heat exchange between solid parts and the hydraulic fluid in the case.

the cylinder block valve plate interface. When the leakage flow enters in the case, its temperature is different from the temperature in the high pressure port, because during its path through the lubricating interfaces it is heated up by the viscous friction. However, for practical calculation, it is reasonable to assume that the temperature of the leakage flow is not affected by the viscous dissipation and therefore that the hydraulic fluid enters into the case volume at the same temperature of the outlet port, $T_{o}$; to compensate for this approximation it is assumed that all the heat generated in the lubricating interfaces is transferred to the solid parts. The rate of heat flow carried out by the external leakage is expresses as follows

$$
\dot{Q}_{l, e x t}=\dot{m}_{l, e x t}\left[c_{p}\left(T_{o}-T_{c}\right)\right]
$$

The case volume is subjected to natural and forced convection. The forced convection is generated by the fresh oil flowing from the inlet to the outlet port through the displacement chambers and it was already introduced in the previous section during the analysis of the heat exchange of the displacement volume, Eq. 7. This second cooling effect actually takes place inside the cylinder block, valve plate and end case bodies, rather inside the oil in the case. Nevertheless, since it was assumed that all the heat generated by viscous friction in the lubricating interfaces is transferred to the solid parts in the rotating kit, it is reasonable to think this convection effect just as part of the total heat which is not transferred to the fluid in the case. In this way the rate of heat flow associated with this cooling action is expressed with Eq. 7, but with opposite sign

$$
\dot{Q}_{f c v}=-\frac{z}{2} \alpha_{D C}\left(A_{D C}^{-}+A_{o c}\right)\left(T_{c}-T_{o}\right)
$$

Natural convection is assumed for the heat exchange of the outer surface of the machine case with the ambience. The associated rate of heat flow is expressed as follows:

$$
\dot{Q}_{n c v}=-\alpha_{h} A_{h}\left(T_{c}-T_{a}\right)
$$

The natural convection coefficient can be estimated with the correlation for natural convection over a vertical plane [3].

$$
\alpha_{h}=0.478 \mathrm{Gr}^{0.25}
$$

where the Grashof number is defined as follows

$$
\mathrm{Gr}=\frac{g L^{3}\left(T_{c}-T a\right)}{v^{2} T_{a}}
$$

where $L$ is a characteristic dimension of the housing, $g$ the gravity acceleration and $v$ the kinematic viscosity of the air. A value of about $25 \mathrm{~W} / \mathrm{m}^{2} \mathrm{~K}$ is usually a good estimate for natural convection.

Thermal radiation is the last effect which impacts the case temperature. Even though radiation heat transfer is proportional to the difference of the fourth power of the absolute temperatures, it is usually the smallest contribution to the overall heat exchange, but it is not small enough to be totally neglected. The expression for the radiation heat transfer is the following:

$$
\dot{Q}_{R}=-\sigma \varepsilon A_{h}\left(T_{c}^{4}-T_{a}^{4}\right)
$$

The energy balance for the case control volume becomes therefore the following:

$$
\begin{array}{r}
\dot{m}_{l, e x t}\left[c_{p}\left(T_{o}-T_{c}\right)\right]-\alpha_{h} A_{h}\left(T_{c}-T_{a}\right) \\
-z \alpha_{D C} A_{D C}^{-}\left(T_{c}-\frac{T_{i}+T_{o}}{2}\right)-\sigma \varepsilon A_{h}\left(T_{c}^{4}-T_{a}^{4}\right) \\
+\Phi_{c, v}+\Phi_{s, s}+\Phi_{p, c}+\Phi_{c h}=0
\end{array}
$$

The rate of heat flow associated with the viscous dissipation in the piston / cylinder interface is represented by $\Phi_{p, c}$; analogous definitions apply for $\Phi_{s, s}$ and $\Phi_{c, v}$ for the slipper / swash plate and the cylinder block / valve plate interface, respectively. The rate of heat flow associated with churning losses were instead indicated with $\Phi_{c h}$. The calculation of these sources of heat will be discussed in detail in sections 3.2 and 3.3. Furthermore it shall be noticed that the entalphy difference does not include the term related with the fluid compression, since the oil enters and exits from the case volume at the same pressure.

\subsection{Calculation of the case and outlet temperatures}

Equations 9 and 16 define a system of two equations with the two unknowns $T_{c}$ and $T_{o}$. Due to the non-linearity of the equations an iterative procedure has been used to solve the problem.

\section{The estimation of the power losses in the axial piston machine}

Axial piston pumps and motors are affected by two sources of power loss: mechanical and volumetric losses. As already anticipated in section 2 volumetric losses are represented by external and internal leakage and by the effect of the oil compressibility. Mechanical losses occur due to friction in the lubricating interfaces, churning losses, drag due fluid flow from inlet to outlet and losses in shaft bearings and seals. In 
this study the losses associated with drag and the losses in shaft bearings and seals are neglected, i.e. only the two major sources of mechanical losses are considered; losses due to friction in lubricating interfaces and churning losses.

Since the oil temperature in the case and displacement volume is affected by many of the aforementioned losses, this section illustrates how they are calculated through computer simulation. In this way the results of this study can be presented into a bigger picture, which extends to the prediction of the machine's overall efficiency.

\subsection{Prediction of the effective outlet flow and associated volumetric losses}

The prediction of the effective volumetric flow rate and volumetric losses due to compressibility, non ideal timing and internal leakage are based on a lumped parameters approach. The control volume in this case is defined just by the fluid in the displacement chamber, as illustrated in Fig. 7. The actual

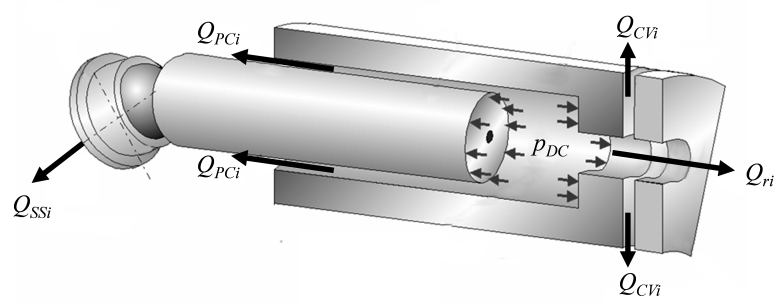

Figure 7: Modeling approach used to predict the lubricating interface performance in axial piston machines.

volumetric flow delivered by the displacement action of the pistons is $Q_{r i}$. However, additional volumetric flows leave the control volume in form of leakage through the piston / cylinder interface $Q_{P C i}$, cylinder block / valve plate interface $Q_{C V i}$ and and slipper / swash plate interface $Q_{S S i}$. The sum of these leakage flows for all the displacement chambers determines the volumetric external leakage flow:

$$
Q_{l, e}=\sum_{i=1}^{z}\left(Q_{P C i}+Q_{C V i}+Q_{S S i}\right)
$$

Changes in the amount of fluid in the control volume lead to changes in the displacement chamber pressure $p_{D C}$ as indicated by the pressure build-up equation:

$$
\frac{\mathrm{d} p_{D C}}{\mathrm{~d} t}=\frac{K}{V}\left(Q_{r i}-Q_{P C i}-Q_{C V i}-Q_{S S i}\right)
$$

where $K$ is the bulk modulus of the hydraulic fluid and $V$ is the instantaneous volume of the chamber. The volumetric flow $Q_{r i}$ can be thought as a sum of the volumetric flow coming from the inlet $Q_{i}$ and the volumetric flow heading to the outlet $Q_{o}$. These two volumetric flows depend on the pressure differentials between the displacement chamber and the relative ports and are modeled with the equation describing the turbulent flow through an orifice

$$
\begin{array}{r}
Q_{r i}=Q_{r i, i}+Q_{r i, o}= \\
=A_{i} \alpha_{D, i} \sqrt{\frac{2\left(p_{D C}-p_{i}\right)}{\rho} \operatorname{sgn}\left(p_{D C}-p_{i}\right)+} \\
+A_{o} \alpha_{D, o} \sqrt{\frac{2\left(p_{D C}-p_{o}\right)}{\rho}} \operatorname{sgn}\left(p_{D C}-p_{o}\right)
\end{array}
$$

In Eq. $19 \alpha_{D, i}$ and $\alpha_{D, o}$ are the discharge coefficients, while $A_{i}$ and $A_{o}$ are the orifice areas, determined by the geometry of the valve plate.

The combination of Eq. 18 and 19 allows the instantaneous pressure in the displacement chamber and the effective outlet flow to be calculated over one shaft revolution. More details about the modeling approach and the solution method can be found for example in [4]. Figure 8 illustrates the predicted volumetric outlet flow for a $75 \mathrm{cc}$ unit at $2000 \mathrm{rpm}$ and 300 bar of differential pressure. The combined effect effect of

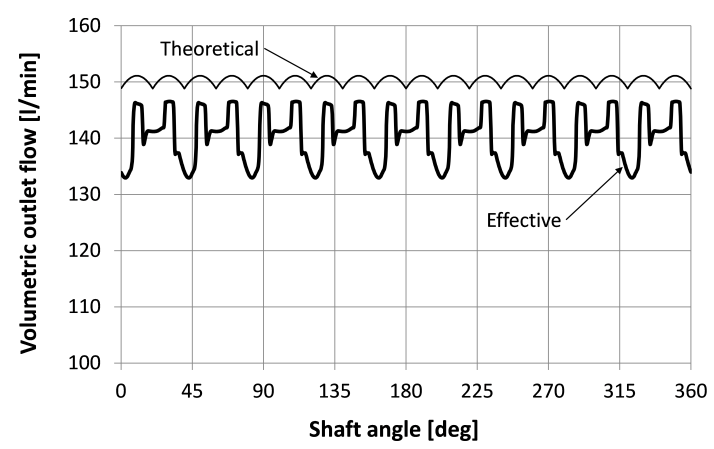

Figure 8: Effective and theoretical outlet flow for a $75 \mathrm{cc}$ unit, at 2000 rpm,maximum displacement angle and 300 bar of differential pressure.

compression loss, internal leakage and backflow due to non ideal timing (shown in Fig. 4 for one displacement chamber), determines an average volumetric outlet flow rate $Q_{o, e}$ that is lower than the theoretical $Q_{o, t h}$. The power loss associated with this lower volumetric flow rate is calculated as follows

$$
P_{l, c i}=\left(Q_{o, t h}-Q_{l, e}-Q_{o, e}\right) \Delta p
$$

\subsection{Prediction of power losses in the lubricating inter- faces of axial piston machines}

The prediction of the energy dissipation and leakage flows in the three lubricating machine interfaces (piston/cylinder, cylinder block/valve plate and slipper/swash plate) represents an extremely difficult problem because the fluid film thickness is determined by the combined effect of a variety of physical phenomena. Recent works of the author's research group have demonstrated that the fluid film behavior can be predicted with good level of accuracy only when multiphysics simulation model are introduced [1], [5], [6] for the piston / cylinder interface, [7], [8] for the slipper / swash plate interface and [9], [10], [2] for the cylinder block / valve plate 
interface. The three interfaces are subject to the same physical phenomena and therefore can be modeled using the same basic structure.

An overview of the modeling approach is represented in Fig. 9. Four main modules, coupled together, account for all the

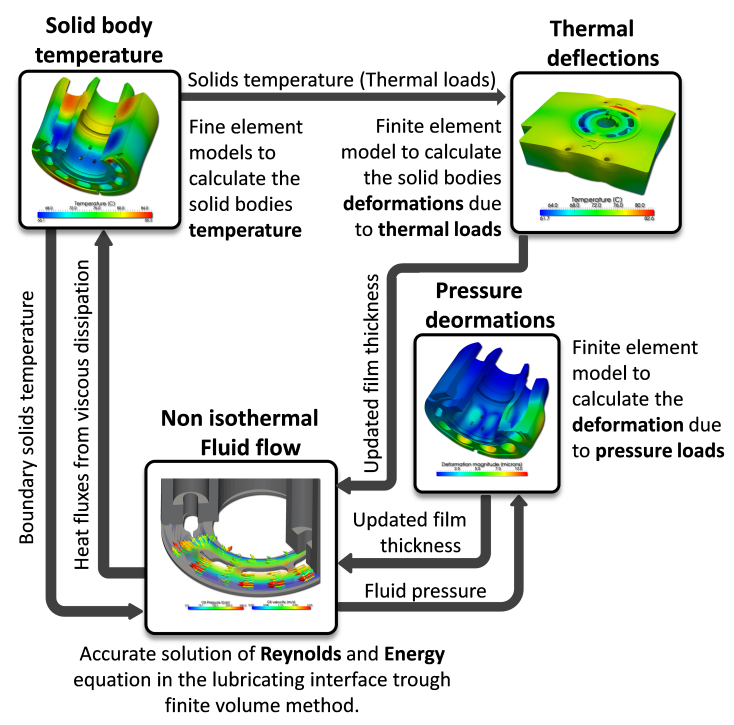

Figure 9: Modeling approach used to predict the lubricating interface performance in axial piston machines.

main physical phenomena in the lubricating interfaces. The first module solves for the non-isothermal fluid flow in the lubricating interfaces, the governing equations are the Reynolds and the Energy equations. The Reynolds equation is solved iteratively by changing the normal squeeze term until the external loads on the solid parts are balanced by the pressure field in the lubricant. A modified version of the standard Reynolds equation has been derived, in order to account for any alteration of the surfaces in contact with the clearance and to allow the viscosity to change along the film. Furthermore, the fluid viscosity is calculated with experimentally derived correlation and it is estimated as a function of pressure and temperature. The energy equation accounts for conductive heat transfer between fluid film and solid parts, convective effects determined by the fluid velocity field and heat generation due to the viscous dissipation; this last term is fundamental for the present work and it will be discussed with more detail later. Thanks to the solution of the non-isothermal fluid flow, the main oil properties (pressure, temperature, viscosity, velocity) can be calculated as function of the operating condition; this allows for the load carrying ability, leakages and torque losses to be estimated for all the three lubricating interfaces.

From the knowledge of the pressure field, the elastic deformations of the solid parts are calculated using an in house finite element solver. The deformations of the surfaces in contact with the lubricant are extracted and used to correct the film thickness in the fluid flow module. However, pressure and deformation mutually influence each other and therefore a converged solution can be found only by solving a fluid structure interaction problem or, more precisely, an elastohydrodynamic lubrication problem. This is achieved thanks to a partitioned fluid structure interaction algorithm: two separate solver are used for the fluid mechanic and the solid mechanic problems and the solutions are coupled together through the interface between fluid and structure; an under-relaxed iterative procedure ensures the convergence of the solution.

Also the heat transfer is characterized by an interaction between the lubricating interface and the solids. In the solution of the Energy equation the surface temperatures of the solid parts are important boundary conditions that strongly affect the calculated temperature field. On the other hand, the mechanical dissipated in the fluid flow generates heat, which heads to the solid parts. The rate of heat flow released by the viscous friction can be calculated using the mechanical dissipation function for a Newtonian fluid [3]. The typical assumptions that the lubrication theory allows to make, simplify the expression of the mechanical dissipation as follows:

$$
\begin{aligned}
& \Phi_{d}=\mu\left[\left(\frac{\partial u}{\partial z}\right)^{2}+\left(\frac{\partial v}{\partial z}\right)^{2}\right] \\
& \Phi_{d}=\mu\left[\left(\frac{\partial u}{\partial z}\right)^{2}+\left(\frac{\partial v}{\partial z}\right)^{2}+\frac{4}{3}\left(\frac{u}{r}\right)^{2}+\left(\frac{v}{r}\right)^{2}\right]
\end{aligned}
$$

In Eq. 21 the first expression is used for a Cartesian reference frame, the second for a cylindrical reference frame; $u$ and $v$ are fluid velocity components along the film and $z$ is the direction of the film thickness.

From Eq. 21, the heat fluxes towards the solid parts can be calculated and applied as boundary conditions to solve for the temperature fields in all the parts of the rotating kit. A finite element solver based on the Galerkin formulation of the finite element method has been specifically developed for this purpose. From the knowledge of temperature fields in the solids, the thermal loads associated to the temperature induced strains are calculated through the coefficient of linear expansion of the materials. The resulting thermal deflection of the solid parts are determined thanks to finite element calculation. Likewise the elastic deformation due to pressure, the deflections deriving from the thermal expansion affect the fluid film thickness with substantial modification of the fluid film behavior.

The whole model requires many iterations to reach a converged solution, because just the external loads on the parts can be calculated a priori; all the other variables have to be guessed and updated iteration after iteration. The described modeling approach is quite complex and certainly a thorough description is out of the scope of this paper; more detailed information is addressed to the publications mentioned above.

Using the above very briefly described modeling approach the energy dissipation taking place during steady state operation of the machine can be calculated for all three interfaces according to Eq. 19. In addition the case flow resulting from all three interfaces can be accurately predicted. These values are used as inputs for the in this paper presented model.

\subsection{Prediction of the churning losses in the machine case}

The rotation of the cylinder block together with the reciprocating motion of the pistons in the case filled with hydraulic 
fluid generate power loss, which is usually referred as churning loss. The two major contributions to churning losses are illustrated in Fig. 10.

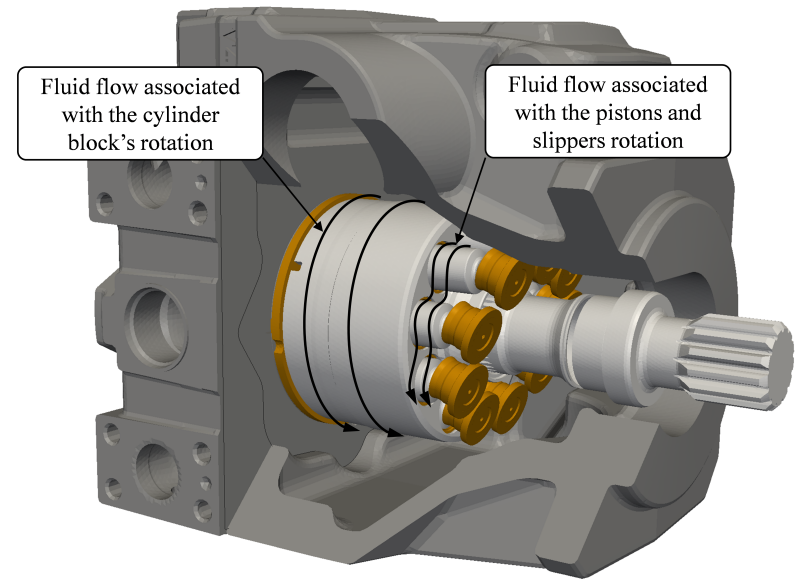

Figure 10: Two main sources of churning losses.

In order to estimate churning losses as a function of the pump design and the working speed, the following model is proposed.

\subsubsection{Churning losses due to the cylinder block rotation}

To determine the power loss due to the rotating cylinder block in the oil filled case, the following assumptions have been made:

- the internal shape of the housing can be well approximated with a cylinder or, in other words, the cylinder block and the internal region of the housing are conformal surfaces;

- the flow is laminar and no major eddies are present. In this way, since the fluid flow is determined by the dragging effect of the cylinder block rotation, the only non zero component of the fluid velocity is in the circumferential direction.

These conditions are usually a reasonable simplification of the problem and lead to acceptable results. With reference to Fig. 11, recalling Eq. 21, when the above mentioned conditions are applied the expression of the viscous dissipation becomes

$$
\Phi_{d}=\mu\left[r \frac{\partial}{\partial r}\left(\frac{v}{r}\right)\right]^{2}
$$

Furthermore, the expression of the oil velocity is

$$
v=\omega R_{B}\left(\frac{R_{B}+t-r}{t}\right)
$$

where $\omega$ is the cylinder block's angular velocity and $t$ the thickness of the gap between cylinder block and internal surface of the case. The mechanical dissipation per unit volume can therefore be defined as

$$
\Phi_{d}=\mu \omega^{2} R_{B}^{2}\left(\frac{R_{B}+t}{R_{B} t}\right)^{2}
$$

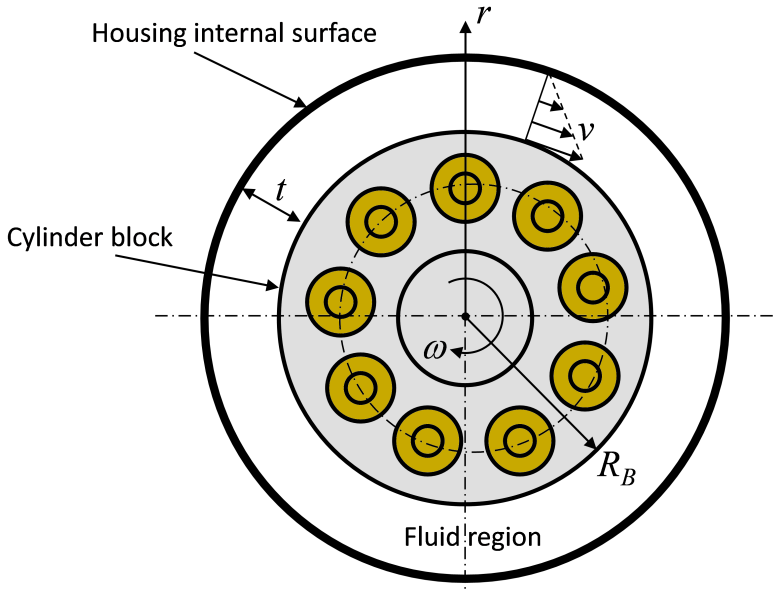

Figure 11: Schematic representation of the flow field between cylinder block's outer surface and housing's inner surface.

The dissipation associated with all the volume of the fluid enclosed by the cylinder block and the housing is determined by the following integral

$$
\Phi_{c h, c b}=\int_{R_{B}}^{R_{B}+t} 2 \pi L \mu \omega^{2} R_{B}^{2}\left(\frac{R_{B}+t}{R_{B} t}\right)^{2} r d r
$$

The result of the integration is the following expression

$$
\Phi_{c h, c b}=-2 \pi L \mu \omega^{2} R_{B}^{2}\left(\frac{R_{B}+t}{t}\right)^{2} \ln \left(1-\frac{t}{R_{B}+t}\right)
$$

By defining the Reynolds number as

$$
R e=\frac{\omega R_{B} t \rho}{\mu}
$$

Eq. 26 becomes

$$
\Phi_{c h, c b}=-\frac{2 \pi L \rho \omega^{3} R_{B}^{3}}{R e}\left(\frac{R_{B}+t}{t}\right)^{2} \ln \left(1-\frac{t}{R_{B}+t}\right)
$$

The thickness of the gap $t$ is usually small and Eq. 26 reduces to the following expression

$$
\Phi_{c h, c b} \approx \frac{2 \pi L \rho \omega^{3} R_{B}^{4}}{R e}
$$

\subsection{Churning losses due to the pistons and slippers mo- tion}

The fluid flow determined by the motion of the pistons and slippers is less likely to meet the conditions listed in the previous section. The pistons and slippers are subjected to friction and pressure drag. However, since the pistons are very closed to each other in circumferential direction, the pressure drag component can be neglected in first approximation, because each piston is shielding the next, located downstream with respect to the rotation direction. This effect is shown schematically in Fig. 12. The problem can be addressed by following 


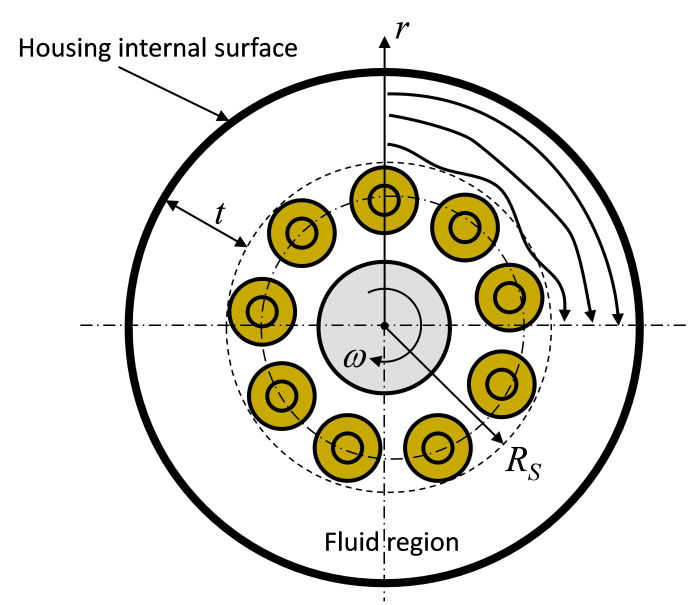

Figure 12: Schematic representation of the flow field between piston \& slipper assemblies and the housing's inner surface.

the same procedure illustrated for the cylinder block churning losses, by defining the radius $R_{S}$ as the outer radius of the slippers, as shown in Fig. 12. Nevertheless, in this situation is reasonable to expect that turbulence is likely to occur.

As suggested by [11], a modified version of Eq. 29 can still be applied for the calculation of the mechanical dissipation under turbulent flow, if the skin friction coefficient $C_{d}(R e)$ is properly estimated. For the laminar case it was $C_{d}=R e / 2$, while in general

$$
\Phi_{c h, c b} \approx C_{d} \pi L \rho \omega^{3} R_{S}^{4}
$$

In this work the skin friction coefficient was calculated according with the correlation proposed by [12]:

$$
\frac{1}{\sqrt{C_{d}}}=2.04+1.78 \ln (\operatorname{Re} \sqrt{C d})
$$

The combination of Eq. 30 and 31 allowed reasonable results to be achieved; however, the effect of turbulence will be further investigated in future studies.

Figure 13 illustrates the dependence of churning losses upon the speed of the machine for a 75cc swash plate type axial piston pump. The trend in Fig. 13 is in very good agreement

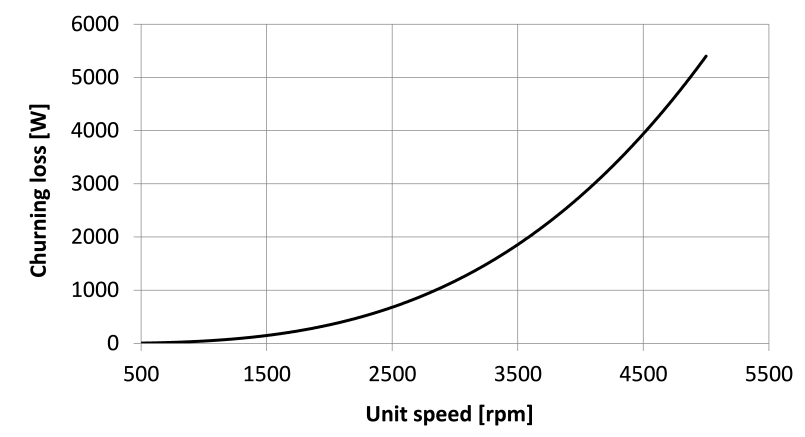

Figure 13: Total churning losses versus machine's speed for a 75 cc swash plate axial piston unit.

with the results found in [13], where the authors measured the difference in input power between full and dry case operation for $233 \mathrm{cc}$ bent axis unit with $45^{\circ}$ angle.

\section{Results}

This section presents a simulation study for a $75 \mathrm{cc}$ unit of current production. The steady state performance of the unit, together with the case and outlet temperature were predicted for the two operating conditions listed in Table 1 and compared with steady state measurements.

Table 1: Definition of the operating conditions considered in the present study.

\begin{tabular}{ccccccc}
\hline $\mathrm{OC}$ & $T_{i}[\mathrm{C}]$ & $\mathrm{n}[\mathrm{rpm}]$ & $p_{i}[\mathrm{bar}]$ & $p_{o}[\mathrm{bar}]$ & $\Delta p[\mathrm{bar}]$ & $\beta[\%]$ \\
\hline 1 & 52.5 & 1000 & 20 & 320 & 300 & 100 \\
\hline 2 & 52.5 & 2000 & 20 & 320 & 300 & 100 \\
\hline
\end{tabular}

Before the presentation of the simulation results, a brief discussion about the estimation of the performance parameters from the steady state measurements is given in the next section.

\subsection{Steady state measurements and data analysis}

Tables 2 and 3 summarize the results of the steady state measurements for the two operating conditions listed in Table 1. The measurements were conducted following the specifications found in [14].

Table 2: Steady state measurement data for OC1.

\begin{tabular}{llcc}
\multicolumn{2}{l}{ Measured quantities } & Value & Unit \\
\hline$\Delta p$ & Pressure differential & 299.8 & bar \\
\hline$n$ & Speed & 1006 & $\mathrm{rpm}$ \\
\hline$Q_{o}$ & Effective volumetric outlet flow rate & 66.4 & $1 / \mathrm{min}$ \\
\hline$Q_{c}$ & Case volumetric flow rate (external leakage) & 1.8 & $1 / \mathrm{min}$ \\
\hline$M_{i}$ & Input torque & 371.4 & $\mathrm{Nm}$ \\
\hline$T_{i}$ & Inlet temperature & 52.5 & ${ }^{\circ} \mathrm{C}$ \\
\hline$T_{o}$ & Outlet temperature & 57.1 & ${ }^{\circ} \mathrm{C}$ \\
\hline$T_{c}$ & Case temperature & 64.9 & ${ }^{\circ} \mathrm{C}$ \\
\hline Derived quantities & Value & $\mathrm{Unit}$ \\
\hline$V_{d}$ & Derived displacement & 72.8 & $\mathrm{cc} / \mathrm{rev}$ \\
\hline$P_{i, t h}$ & Theoretical input power & 36.6 & $\mathrm{~kW}$ \\
\hline$Q_{o, t h}$ & Theoretical volumetric flow rate & 73.2 & $1 / \mathrm{min}$ \\
\hline$M_{1, t h}$ & Theoretical torque & 347.3 & $1 / \mathrm{min}$ \\
\hline$P_{o}$ & Output power & 33.2 & $\mathrm{~kW}$ \\
\hline$P_{l, Q}$ & External leakage power loss & 0.90 & $\mathrm{~kW}$ \\
\hline$P_{l, m h}$ & Mechanical power loss & 2.54 & $\mathrm{~kW}$ \\
\hline$P_{l, c i}$ & Power loss due to Compressibility \& internal leakage & 2.4 & $\mathrm{~kW}$ \\
\hline$P_{l, t o t}$ & Total power loss & 5.9 & $\mathrm{~kW}$ \\
\hline & & &
\end{tabular}

The derived displacement was determined through the Toet method, for more details see [15]. The theoretical input torque and the theoretical volume flow rate were calculated through the derived displacement volume as follows

$$
M_{i, t h}=\frac{\Delta p V_{d}}{2 \pi} \quad Q_{o, t h}=\frac{\omega V_{d}}{2 \pi}
$$


Table 3: Steady state measurement data for OC2.

\begin{tabular}{llcc}
\multicolumn{2}{l}{ Measured quantities } & Value & Unit \\
\hline$\Delta p$ & Pressure differential & 299.8 & bar \\
\hline$n$ & Speed & 2008 & $\mathrm{rpm}$ \\
\hline$Q_{o}$ & Effective volumetric outlet flow rate & 139.2 & $1 / \mathrm{min}$ \\
\hline$Q_{c}$ & Case volumetric flow rate (external leakage) & 2.5 & $1 / \mathrm{min}$ \\
\hline$M_{i}$ & Input torque & 376.9 & $\mathrm{Nm}$ \\
\hline$T_{i}$ & Inlet temperature & 53.2 & ${ }^{\circ} \mathrm{C}$ \\
\hline$T_{o}$ & Outlet temperature & 57.3 & ${ }^{\circ} \mathrm{C}$ \\
\hline$T_{c}$ & Case temperature & 72.5 & ${ }^{\circ} \mathrm{C}$ \\
\hline Derived quantities & Value & $\mathrm{Unit}$ \\
\hline$V_{d}$ & Derived displacement & 74.1 & $\mathrm{cc} / \mathrm{rev}$ \\
\hline$P_{i, t h}$ & Theoretical input power & 74.3 & $\mathrm{~kW}$ \\
\hline$Q_{o, t h}$ & Theoretical volumetric flow rate & 148.8 & $1 / \mathrm{min}$ \\
\hline$M_{1, t h}$ & Theoretical torque & 353.5 & $1 / \mathrm{min}$ \\
\hline$P_{o}$ & Output power & 69.7 & $\mathrm{~kW}$ \\
\hline$P_{l, Q}$ & External leakage power loss & 1.2 & $\mathrm{~kW}$ \\
\hline$P_{l, m h}$ & Mechanical power loss & 4.9 & $\mathrm{~kW}$ \\
\hline$P_{l, c i}$ & Power loss due to Compressibility \& internal leakage & 3.4 & $\mathrm{~kW}$ \\
\hline$P_{l, t o t}$ & Total power loss & 9.6 & $\mathrm{~kW}$ \\
\hline & & & \\
\hline
\end{tabular}

The theoretical input power and the actual output power were derived according to Eq. 33:

$$
P_{i, t h}=\omega M_{i, t h} \quad P_{o}=\Delta p Q_{o}
$$

The external leakage and mechanical losses were calculated as follows

$$
P_{l, l, e}=\Delta p Q_{c} \quad P_{l, m h}=\omega\left(M_{i}-M_{i, t h}\right)
$$

The power loss due to compressibility and internal leakage were calculated using Eq. 35 considering the difference between the theoretical volumetric flow rate

$$
P_{l, c i}=\Delta p\left(Q_{o, t h}-Q_{l}-Q_{o}\right)
$$

\subsection{Simulation results}

Tables 4 and 5 summarize the simulation results for the two operating conditions listed in Table 1. The simulation were run with the same inlet temperature, speed and differential pressure of the corresponding measurement. For both the operating conditions the prediction of the overall performance of the axial piston unit is in excellent agreement with the measurements.

The simulation model tends to underestimate the case flow with an error of about $20 \%$, which is reasonable considering the complexity of the prediction of the fluid film thickness discussed in Sec. 3.2. The outlet flow is predicted almost exactly; the simulation model also matches quite well the compressibility and internal leakage losses, which represent a very important source of power loss of the unit.

Looking at the total mechanical loss, the simulation predictions are lower than the values derived from the measured data, but this is justified by the fact that the simulation model does not account for the additional mechanical losses in the machine. Moreover, the value calculated from the measurements is affected by the derived displacement in Eq. 32,

Table 4: Simulation results for OC1.

\begin{tabular}{llcc}
\multicolumn{2}{l}{ Simulation input } & Value & Unit \\
\hline$\Delta p$ & Pressure differential & 300.0 & bar \\
\hline$n$ & Speed & 1000.0 & $\mathrm{rpm}$ \\
\hline$T_{i}$ & Inlet temperature & 52.5 & ${ }^{\circ} \mathrm{C}$ \\
\hline Simulation predictions & Value & Unit \\
\hline$Q_{o}$ & Volumetric outlet flow rate & 67.2 & $1 / \mathrm{min}$ \\
\hline$P_{l, m h, P C}$ & Mechanical loss p/c & 0.610 & $\mathrm{~kW}$ \\
\hline$P_{l, m h, S S}$ & Mechanical loss s/s & 0.250 & $\mathrm{~kW}$ \\
\hline$P_{l, m h, C V}$ & Mechanical loss c/v & 0.430 & $\mathrm{~kW}$ \\
\hline$P_{l, c h}$ & Churning losses & 0.052 & $\mathrm{~kW}$ \\
\hline$P_{l, m h}$ & Total mechanical loss & 1.375 & $\mathrm{~kW}$ \\
\hline$Q_{l, e}$ & Total external leakage & 1.34 & $1 / \mathrm{min}$ \\
\hline$P_{l, l, e}$ & External leakage loss & 0.67 & $\mathrm{~kW}$ \\
\hline$P_{l, c i}$ & Compressibility \& internal leakage loss & 3.32 & $\mathrm{~kW}$ \\
\hline$P_{l, t o t}$ & Total power loss & 5.36 & $\mathrm{~kW}$ \\
\hline$T_{o}$ & Outlet temperature & 56.3 & ${ }^{\circ} \mathrm{C}$ \\
\hline$T_{c}$ & Case temperature & 63.4 & ${ }^{\circ} \mathrm{C}$ \\
\hline & & &
\end{tabular}

Table 5: Simulation results for OC2.

\begin{tabular}{llcc}
\multicolumn{2}{l}{ Simulation input } & Value & Unit \\
\hline$\Delta p$ & Pressure differential & 300.0 & bar \\
\hline$n$ & Speed & 2000.0 & $\mathrm{rpm}$ \\
\hline$T_{i}$ & Inlet temperature & 53.2 & ${ }^{\circ} \mathrm{C}$ \\
\hline Simulation predictions & Value & $\mathrm{Unit}$ \\
\hline$Q_{o}$ & Volumetric outlet flow rate & 140.5 & $\mathrm{l} / \mathrm{min}$ \\
\hline$P_{l, m h, P C}$ & Mechanical loss p/c & 0.97 & $\mathrm{~kW}$ \\
\hline$P_{l, m h, S S}$ & Mechanical loss s/s & 0.55 & $\mathrm{~kW}$ \\
\hline$P_{l, m h, C V}$ & Mechanical loss c/v & 1.06 & $\mathrm{~kW}$ \\
\hline$P_{l, c h}$ & Churning losses & 0.340 & $\mathrm{~kW}$ \\
\hline$P_{l, m h}$ & Total mechanical loss & 2.92 & $\mathrm{~kW}$ \\
\hline$Q_{l, e}$ & Total external leakage & 2.00 & $1 / \mathrm{min}$ \\
\hline$P_{l, l, e}$ & External leakage loss & 1.00 & $\mathrm{~kW}$ \\
\hline$P_{l, c i}$ & Compressibility \& internal leakage loss & 3.92 & $\mathrm{~kW}$ \\
\hline$P_{l, t o t}$ & Total power loss & 7.84 & $\mathrm{~kW}$ \\
\hline$T_{o}$ & Outlet temperature & 56.0 & ${ }^{\circ} \mathrm{C}$ \\
\hline$T_{c}$ & Case temperature & 74.0 & ${ }^{\circ} \mathrm{C}$ \\
\hline
\end{tabular}


which is just an approximation of the actual displacement of the machine, not an exact number. For example, just $1 \mathrm{cc} / \mathrm{rev}$ of difference in the derived displacement can change the derived mechanical loss of more than $500 \mathrm{~W}$. The maximum error on the outlet and case temperature predictions is below the $2{ }^{\circ} \mathrm{C}$ overall, which confirms a remarkable accuracy of the thermal model.

In order to further confirm the fidelity of the developed model, the case and outlet temperatures were predicted for a fixed speed of $2000 \mathrm{rpm}$ and a variety of differential pressures. The comparison between the measurements and the simulation results are illustrated in Fig. 14 and 15.

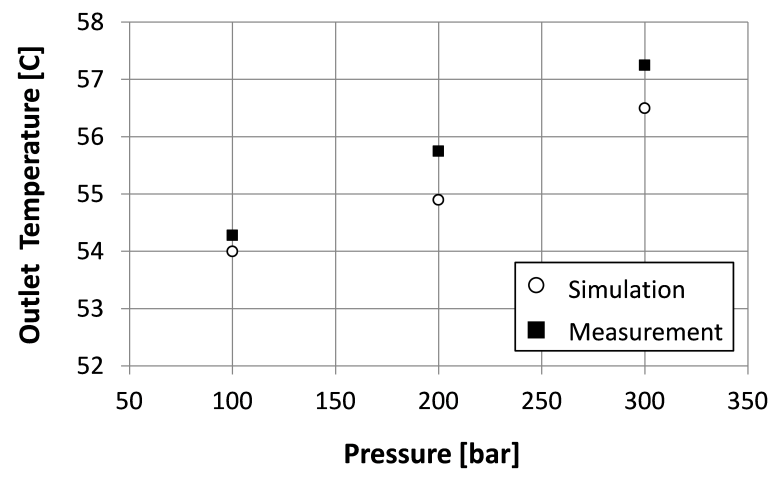

Figure 14: Comparison of the predicted and measured outlet temperature for maximum displacement, 2000 rom and different operating pressures.

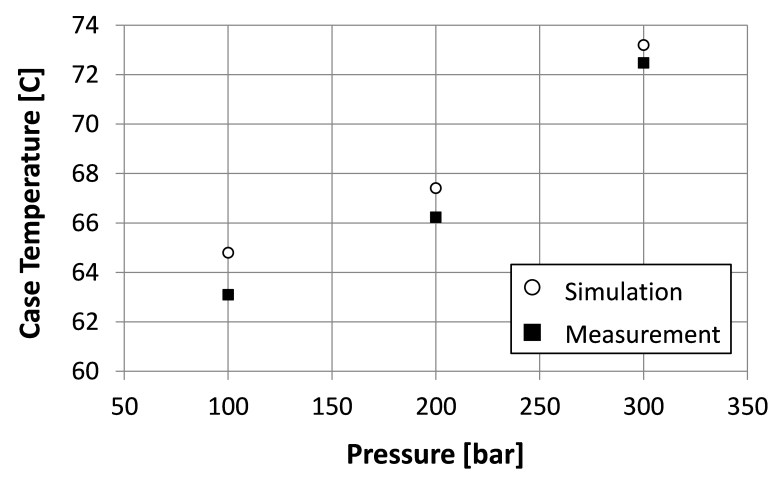

Figure 15: Comparison of the predicted and measured case temperature for maximum displacement, 2000 rom and different operating pressures.

Also in this case the maximum error between the simulation and measurements is limited to $2{ }^{\circ} \mathrm{C}$. This not only further confirms the validity of the thermal model, but also highlights the ability of the fluid structure interaction model for the lubricating interfaces to predict with high accuracy the mechanical losses. If this was not the case, major discrepancies would have been observed between simulation and measurements.

\section{Conclusion}

A thermal model for the prediction of the temperature in the case and outlet port of axial piston machines under steady state operation was described. The thermal model was coupled with simulation models for the estimation of the effective flow rate of the machine and for the prediction of the performance of the three main lubricating interfaces.

The prediction of the overall machine efficiency and the working temperature in the outlet and case volumes was in very good agreement with the measurements, for many different operating conditions. The developed model has confirmed that the accuracy required for virtual prototyping of axial piston pumps and motors has been successfully achieved.

\section{References}

[1] Matteo Pelosi and Monika Ivantysynova. Surface Deformation Enables High Pressure Operation of Axial Piston Pumps. In ASME/Bath Symposium on Fluid Power and Motion Control, Arlington, VI, USA, 2011.

[2] Marco Zecchi and Monika Ivantysynova. A novel approach to predict the cylinder block / valve plate interface performance in swash plate type axial piston machines. In ASME/Bath Symposium on Fluid Power and Motion Control, pages 13-28, 2012.

[3] Frank P Incropera, David P DeWitt, Theodore L Bergman, and Adrienne S Lavine. Fundamentals of Heat and Mass Transfer, volume 6th of Dekker Mechanical Engineering. John Wiley \& Sons, 2007.

[4] Uwe Wieczorek and Monika Ivantysynova. Computer aided optimization of bearing and sealing gaps in hydrostatic machines - The simulation tool CASPAR. International Journal of Fluid Power, 3(1):7-20, 2002.

[5] Matteo Pelosi and Monika Ivantysynova. The Influence of Pressure and Thermal Deformation on the Piston/Cylinder Interface Film Thickness. In 52nd $\mathrm{Na}$ tional Conference on Fluid Power, 2011.

[6] Matteo Pelosi. An Investigation on the Fluid-Structure Interaction of Piston/Cylinder Interface. Phd thesis, Purdue University, 2012.

[7] Andrew Schenk and Monika Ivantysynova. An Investigation of the Impact of Elastohydrodynamic Deformation on Power Loss in the Slipper Swashplate Interface. In 8th JFPS International Symposium on Fluid Power, Okinawa, Japan, 2011.

[8] Andrew Schenk and Monika Ivantysynova. The influence of swashplate elastohydrodynamic deformation. In 7th FPNI PhD Symposium, Reggio Emilia, Italy, 2012.

[9] Marco Zecchi and Monika Ivantysynova. Cylinder block/valve plate interface - A novel approach to predict thermal surface loads. In 8th IFK International Conference on Fluid Power, pages 285-298, Dresden, Germany, 2012. 
[10] Marco Zecchi and Monika Ivantysynova. An investigation of the impact of micro surface shaping on the cylinder block/valve plate inter-face performance through a novel thermo-elasto-hydrodynamic model. In 7 th FPNI PhD Symposium, pages 589-610, 2012.

[11] James Vkzncik. Prediction of windage power loss in alternators. Technical Report October, NASA, WASHINGTON, D. C., 1968.

[12] Carl Gazley. Heat-Transfer Characteristics of the Rotation and Axial Flow Between Concentric Cylinders. Trans. ASME, 80(1):79-90, 1958.

[13] Robert Rahmfeld, Marsch Siinje, Wilhelm Giillner, Thorsten Lang, Thomas Dopichay, and Johannes Untch. Mehr Effizienz bei hydrostatischen Einheiten. $O+P \ddot{O} l$ hydraulik und Pneumatik, 7(8):22-27, 2012.

[14] ISO. Hydraulic fluid power - Positive motors and integral transmissions steady-state performance. Technical report, International Organization For Standardization, 2005.

[15] Jaroslav Ivantysyn and Monika Ivantysynova. Hydrostatic Pumps and Motors. Akademia Books International, New Delhi, India, 2001.

\section{Nomenclature}

\begin{tabular}{lll}
\hline Symbols & Denotation & Unit \\
\hline$z$ & number of pistons & {[]} \\
$\dot{m}$ & mass flow rate & {$[\mathrm{kg} / \mathrm{s}]$} \\
$\dot{Q}$ & rate of heat flow & {$[\mathrm{J} / \mathrm{s}]$} \\
$\dot{W}$ & rate of work & {$[\mathrm{J} / \mathrm{s}]$} \\
$P$ & power & {$[\mathrm{J} / \mathrm{s}]$} \\
$p$ & pressure & {$[\mathrm{Pa}]$} \\
$n$ & rotational velocity & {$[\mathrm{rpm}]$} \\
$\omega$ & angular velocity & {$[\mathrm{rad} / \mathrm{s}]$} \\
$\Delta p$ & pressure differential & {$[\mathrm{Pa}]$} \\
$T$ & temperature & {$\left[{ }^{\circ} \mathrm{C}\right]$}
\end{tabular}

\begin{tabular}{|c|c|c|}
\hline$\mu$ & dynamic viscosity & {$[\mathrm{Pa} \mathrm{s}]$} \\
\hline$v$ & kinematic viscosity & {$\left[\mathrm{m}^{2} / \mathrm{s}\right]$} \\
\hline$\rho$ & density & {$\left[\mathrm{kg} / \mathrm{m}^{3}\right]$} \\
\hline$h$ & enthalpy & {$[\mathrm{J} / \mathrm{kg}]$} \\
\hline$c_{p}$ & specific heat capacity & {$\left[\mathrm{J} / \mathrm{kg}^{\circ} \mathrm{C}\right]$} \\
\hline$\alpha$ & convection coefficient & {$\left[\mathrm{W} / \mathrm{m}^{2 \circ} \mathrm{C}\right]$} \\
\hline$\gamma$ & volumetric expansion coeff. & [] \\
\hline$\beta$ & swash plate angle & {$[\%]$} \\
\hline$V_{0}$ & displacement volume & {$\left[\mathrm{m}^{3} / \mathrm{rev}\right]$} \\
\hline$V_{d}$ & derived displacement volume & {$\left[\mathrm{m}^{3} / \mathrm{rev}\right]$} \\
\hline$Q$ & volumetric flow rate & {$\left[\mathrm{m}^{3} / \mathrm{s}\right]$} \\
\hline$A$ & area & {$\left[\mathrm{m}^{3} / \mathrm{s}\right]$} \\
\hline$K$ & isothermal bulk modulus & {$[\mathrm{Pa}]$} \\
\hline$V$ & volume & {$\left[\mathrm{m}^{3}\right]$} \\
\hline$\Phi_{d}$ & mechanical dissipation & {$[\mathrm{W}]$} \\
\hline$C_{d}$ & drag coefficient & [] \\
\hline$L$ & cylinder block length & {$[\mathrm{m}]$} \\
\hline$R_{B}$ & cylinder block outer radius & [m] \\
\hline$R_{S}$ & slippers outer radius & [m] \\
\hline$t$ & $\begin{array}{l}\text { radial gap between cylinder block } \\
\text { and housing }\end{array}$ & {$[\mathrm{m}]$} \\
\hline $\operatorname{Re}$ & Reynolds number & [] \\
\hline Subscripts & Denotation & \\
\hline$i$ & inlet & \\
\hline$o$ & outlet & \\
\hline$c$ & case & \\
\hline$h$ & housing & \\
\hline$a$ & ambient & \\
\hline$t h$ & theoretical & \\
\hline$l$ & loss & \\
\hline$m h$ & mechanical & \\
\hline$c i$ & $\begin{array}{l}\text { compressibility and internal leak- } \\
\text { age }\end{array}$ & \\
\hline$D C$ & displacement chamber & \\
\hline$P C$ & piston / cylinder interface & \\
\hline$C V$ & cylinder / valve plate interface & \\
\hline$S S$ & slipper /swash plate & \\
\hline$c h$ & churning & \\
\hline$n c v$ & natural convection & \\
\hline$f c v$ & forced convection & \\
\hline
\end{tabular}

